\title{
Stability in Friendship Patterns Among Kindergarteners: A Short-Term Longitudinal Study
}

\author{
Mi Hyun Park, Kyung Ja Park \\ Department of Child \& Family Studies, Yonsei University, Seoul, Korea \\ 유아의 친구관계 안정성에 대한 단기 종단적 탐색 \\ 박미현, 박경자 \\ 연세대학교 아동·가족학과
}

Objective: This two-wave study examined stability in kindergarteners' friendship patterns over 5 months.

Methods: Participants were 501 five-year-old children (262 girls and 239 boys) attending kindergartens in Seoul, Incheon, and Kyounggi provinces in Korea. Each child nominated three individuals as his/her friends in July, and again in December of 2013. Depending on the presence/ absence of friendships and the mutuality of identifying friends, the children's friendship patterns were categorized into five groups: stable, fluid, loss, gain, and friendless. The data were analyzed by descriptive statistics, and chi-square tests.

Results: Results revealed stability, as well as changes in friendship patterns, among kindergarteners over the 5 -month period. The stable friendships, those that maintained the same friend(s) in both waves, was $43.7 \%$, the fluid friendships, those that changed friends over the 5 month period was $18 \%$, the gain friendships, those who had newly developed friends in wave 2 was $17 \%$, and the loss friendships, those who had friends at wave 1 but lost friends at wave 2, was $9.8 \%$. The friendless, those that had no friends in both waves, was $11.5 \%$.

Conclusion: Results showed that kindergarteners were capable of maintaining and making new friends over a 5-month period.

Keywords: Friendship of kindergarteners, Friendship stability patterns, Short-term longitudinal studyworks$$
\text { 서론 }
$$

유아가 자라면서 가장 먼저 접하게 되고 영향을 많이 끼치는 사람은 부모와 또래이다. 부모는 유아와 수직적인 관계를 형 성하고 사회의 가치나 규범을 전수하는 역할을 하는 반면, 또 래는 수평적인 관계를 통해 의사소통 능력, 갈등 관리, 사회

Corresponding Author: Mi Hyun Park, Department of Child and Family Studies, Yonsei University, 134 Shinchon-dong, Seodaemun-Gu, Seoul 120-749, Korea

E-mail: kssopi@empal.com
\end{abstract}

적 문제 해결 능력, 조망 수용의 발달을 촉진시킨다(GiffordSmith \& Brownell, 2003; Rose-Krasnor \& Denham, 2009; Rubin, Coplan, Chen, Buskirk, \& Wojslawowicz Bowker, 2005). 유아는 또래와 자주 만나고 공유 활동을 통한 놀이를 함께 하면서 친 구관계를 형성하게 되는데 유아기의 친구는 친밀감을 발달시 킬 수 있는 발판이 되어 이후 성인이 되었을 때 친밀한 사회

CThe Korean Association of Child Studies

This is an Open Access article distributed under the terms of the Creative Commons Attribution Non-Commercial License (http:// creativecommons.org/licenses/by-nc/4.0) which permits unrestricted noncommercial use, distribution, and reproduction in any medium, provided the original work is properly cited. 
적 관계를 형성하고 유지할 수 있도록 준비시켜 준다(Howes, 2009; Kostelnik, Whiren, Soderman, \& Gregory, 2009). 이러한 측면에서 볼 때, 유아기의 친구관계는 사회적 유능감을 발달 시키고 심리적 안녕감을 유지하는 중요한 요인이라고 할 수 있다.

유아기의 친구관계는 저절로 이루어지는 것이 아니고 개인 의 특성에 따라 영향을 받기 때문에 친구가 많은 유아도 있지 만 친구가 별로 없는 유아도 있다. 친한 친구가 있는지, 없는지 에 따라 유아는 서로 다른 심리사회적 적응 결과를 나타낼 수 있다.

친구관계를 형성하는 것도 중요하지만 친구관계를 오랫동 안 유지하는 것은 서로 간에 친밀감과 정서적 유대감을 발달시 킬 수 있다는 측면에서 의미있는 일이다(Furman, 1996). 시간이 흐름에 따라 동일한 친구와 친구관계를 계속 유지하는 것은 친 구관계의 안정성을 의미한다(Ladd, Kochenderfer, \& Coleman, 1996; Newcomb \& Bagwell, 1995). 반면 친구관계가 종결되거 나 친구가 없다가 있게 되는 것처럼 친구관계의 유대감이 변 화하는 것을 친구관계의 불안정성이라고 일컫는다(Ladd et al., 1996; Poulin \& Chan, 2010). 유아가 친구관계를 유지하려면 상 호간에 관심을 공유하고 자기 노출을 하면서 관계를 지속하려 는 의도적인 노력을 기울여야 한다. 친구관계를 지속시키기 위 해 노력하는 과정에서 유아는 타인의 욕구와 감정을 민감하고 정확하게 인식하는 능력이 발달하게 된다(Newcomb \& Bagwell, 1995). 그리고 친구가 계속 있는 것은 서로를 지지해주는 요인 이 되어 유아가 새로운 환경에 적응하고 심리적 안녕감을 유지 하는데 도움이 될 수 있다(Ladd et al., 1996).

유아의 친구관계는 계속 유지되기도 하지만 시간이 지나면 서 변화하기도 한다. 유사한 성격을 가진 유아들이 서로 친구 관계를 형성하는데, 서로의 관심과 능력이 변하고 새로운 관 심이 생기고, 가치관이나 능력이 발달하면 친하게 지내던 친 구와 관계가 소원해지고 다른 유아와 새롭게 친구관계를 형 성할 수도 있다(Wojslawowicz Bowker, Rubin, Burgess, BoothLaForce, \& Rose-Krasnor, 2006). 처음에는 또래가 놀이하는 것 을 지켜보며 관찰자의 자세를 취하거나 교사에게 의존적인 모 습을 보이다가 시간이 지나면서 친구관계를 형성하는 유아 도 있다. 친구와 잦은 갈등을 일으키거나 갈등을 원만하게 해 결하지 못하는 경우, 친구와 활발한 의사소통을 통해 자신의 생각과 느낌을 주고받으며 적극적으로 친밀감을 높이기 위 한 노력을 기울이지 않은 경우에는 친구를 잃게 될 수도 있다 (Gottman, 1983; Rubin, Bukowski, \& Parker, 2006). 친구를 잃 는 유아 뿐 아니라 사회적 기술이 부족하거나 발달지연, 친구
에 대한 관심 부족 등으로 인해 친구를 계속 사귀지 못하는 유 아도 있을 수 있다. 이처럼 유아기에는 친구관계에 변화가 많 은 시기이므로 이러한 발달적 특성을 고려하여 친구관계의 안 정성 및 변화를 살펴볼 필요가 있다.

유아는 성에 따라 다른 사회화 과정을 경험할 수 있다. 유아 는 놀이 유형, 친구에 대한 인식, 친구와 상호작용하는 양상이 성에 따라 차이가 있을 수 있어 친구관계를 형성하거나 유지 하는 정도도 성에 따라 다를 수 있다. (Ladd et al., 1996; Sebanc, 2003). 친구와 자주 싸우면서 갈등을 일으키면 친구관계가 종 결될 가능성이 높기 때문에 친구관계에서의 안정성이 낮아 질 수 있다(Bukowski, Newcomb, \& Hoza, 1987; Parker \& Asher, 1993). 남아는 여아에 비해 공격성이 높고, 친구와 상호작용할 때도 잦은 갈등을 일으킬 수 있으므로(Ladd et al., 1996; Sebanc, 2003) 여아보다 친구관계가 쉽게 해체될 수 있다. 반면 여아는 친구와 사적인 경험과 비밀을 공유하고 정서적 지지를 보이기 때문에(Erwin, 19931; Sebanc, 2003) 친구 간에 친밀감을 높이 고 관계를 오래 지속시킬 가능성이 있다. 그러나 친구 안정성 에 대한 성차가 발견되지 않았거나(Berndt, Hawkins, \& Hoyle, 1986; Cairns, Leung, Buchanan, \& Cairns, 1995), 여아보다 남아 의 친구관계 안정성이 높다는 상반된 연구 결과들도 보고되고 있다(Benenson \& Christakos, 2003; Rose \& Rudolph, 2006).

이제까지 유아의 친구관계에 대한 선행연구는 대부분 한 시점에서만 친구를 측정하여 친구가 있는지의 여부에 대해 서만 살펴보았다(Mendelson, Aboud, \& Lanthier, 1994). 종단 적으로 친구관계를 조사한 연구도 동일한 유아와 일정 시간 이 경과했을 때 친구관계가 유지되는지의 여부로 친구관계 의 안정성을 정의하고 이들의 적응 정도를 조사하였다(Ladd \& Kochenderfer, 1996; Sebanc, Kearns, Hernandez, \& Galvin, 2007). 그러나 유아의 친구관계 안정성은 두 시점에서 친구의 존재 유무 혹은 동일한 친구와 관계가 유지되는지의 여부와 같은 이분법적인 특성 보다는 유아기의 발달적 특성을 반영하 여 좀 더 다양한 친구관계 유형을 살펴볼 필요가 있다.

이에 본 연구에서는 만 5 세 유아를 대상으로 단기 종단적 인 친구관계 안정성을 파악하여 유아기 친구관계에 대한 발달 적 특성을 이해하고자 하였다. 유아기 초기에 친구관계를 형 성하기 시작하면서 유아기 후기가 되어감에 따라 친구관계가 점차적으로 돈독해지며 서로에 대한 영향력도 커지기 때문에 (Howes, 2009; Ladd et al., 1996) 이 시기의 유아를 대상으로 조 사하고자 하였다. 이를 위해 유아들이 서로 친구로 지명한 친 구가 있는지, 그리고 5개월 후 친구로 지명한 유아가 5개월 전 에 지명한 유아와 동일한지에 따라 친구관계의 안정성 및 변 
화 유형을 살펴보고자 하였다. 이러한 분류체계는 학령기 아 동을 대상으로 한 Wojslawowicz Bowker 등(2006)의 연구와 유 아를 대상으로 한 Proulx와 Poulin (2013)의 연구에 기초하였 다. 또한 친구관계의 안정성이 유아의 성에 따라 차이가 있는 지 파악함으로써 유아기 남아와 여아가 다른 사회화 과정을 경험하게 되는지 이해하고자 하였다. 이를 통해 유아가 원만 한 친구관계를 통해 건강한 심리사회적 발달을 하도록 지도할 수 있고 또래관계에 어려움을 겪은 유아들을 위한 또래관계 중재프로그램 개발에 필요한 기초 자료를 제공하는데 본 연구 의 의의가 있다.

본 연구에서는 단기 종단적으로 친구관계에 있어 변화가 있는지를 살펴보고자 다음과 같은 연구 문제를 설정하였다.

\section{연구문제 1}

단기 종단적으로 유아의 친구 수는 성에 따라 어떠한가?

\section{연구문제 2}

단기 종단적으로 유아의 친구관계의 안정성과 변화는 성에 따라 어떠한가?

\section{연구방법}

\section{1. 연구 대상}

본 연구는 5 개월의 시간 간격을 두고 2 회에 걸쳐 친구관계에 대한 자료를 수집하였는데 2회에 걸쳐 자료가 수집 된 유아는 501 명이었다(남아 239명, 여아 262명). 연구 대상 유아의 평균 월령은 1차 자료수집 시점을 기준으로 70 개월이었다(범위: 65 - 77 개월, 표준편차: 4.0개월).

\section{2. 연구도구}

\section{1) 친구관계의 안정성 및 변화 유형}

친구관계에 있어 안정성 및 변화를 측정하기 위하여 본 연구 자와 연구 보조자 4 명이 7 월과 12 월 중순에 5 개월 간격으로 총 2회 또래 지명법을 통해 유아의 친구를 조사하였다. 또래 지명법은 친구관계를 알아보기 위해 주로 사용되는 방법의 하나로(Lindsey, 2002; Rubin et al., 2006; Shin, Kim, Goetz, \& Vaughn, 2014) 이를 구체적으로 살펴보면 다음과 같다.
각 유아에게 개별적으로 독립된 공간에서 유아 자신이 속 한 학급의 모든 동성 유아의 사진을 보여준 후 모르는 아이가 있는지 확인하였다. 유아가 모르는 아이가 없다고 대답하면 가장 친한 친구를 3 명 지명하도록 하였다.

친구를 동성으로 제한한 이유는 만 3 세부터 동일한 성 집 단에서 상호작용하는 것을 좋아하게 되고(Fabes, Hanish, \& Martin, 2003; Maccoby, 1998), 친구관계를 형성할 때 이성 집 단보다는 동성 집단을 선호한다고 제시한 선행 연구에 근거 하였다(Martin \& Fabes, 2001). 또한 친구 수를 3명으로 제한하 되, 1 명만 지명한 경우에도 더 지명하도록 강요하지 않았다. 이는 좋아하는 친구가 한 명 밖에 없는 유아에게 3 명을 무조건 지명하라고 할 경우, 친구가 아닌 유아의 이름을 지명할 가능 성이 있기 때문이다(Cillessen, 2009).

친구관계에 대한 1 차 측정을 하고 5 개월 후에 각 유아는 위 와 동일한 방법으로 친구를 다시 지명하였다. 이러한 측정시 간 간격은 청소년기 이전의 아동이 친구관계를 형성했다가도 다른 새로운 친구와 친해지면 기존의 친구관계가 해체되는 것 처럼 친구관계가 자주 변화할 수 있기 때문에 이들을 대상으 로 친구관계의 변화유형을 평가할 때는 6 개월 이내에 2 회 이 상 측정하는 방법을 제안한 선행연구에 기초한 것이다(Poulin $\&$ Chan, 2010).

본 연구에서는 학기가 시작된 후 4개월 정도 지나 유아들 이 같은 학급의 또래들에 대해 충분히 알 수 있는 시기인 7월 에 친한 친구를 지명하게 하고, 5 개월 이후에 반복 측정하여 총 2 회 조사하였다. 이 때 두 명의 유아가 서로를 친구라고 상 호 지명하였을 경우에 이를 친구관계로 간주하였다. 친구 관 계의 변화는 두 번의 측정에서 유아가 서로를 친구라고 지명 한 친구가 있는지와 친구로 지명한 유아가 동일한지 변화하였 는지에 따라 다섯 가지 유형으로 구분하였다. 이러한 구분은 친구관계의 안정성과 변화유형 같이 종단적으로 친구관계를 살펴본 선행 연구들에 근거한 방법이다(Proulx \& Poulin, 2013; Wojslawowicz Bowker et al., 2006).

친구관계의 변화유형에 대한 분류의 기준은 Table 1 과 같 다. 이를 구체적으로 살펴보면, 동일한 친구와 5개월 후에도 계속 친구관계를 유지하고 있는 유아들은 친구관계의 변화 유 형에서 '동일한 친구지속 집단(same stable group)'으로 분류하 였고, 친구 관계에서 안정성을 보이는 유아들이다. 유아가 5 개월 후에는 전과 동일하지 않은 친구와 친구관계를 형성하 고 있다면 '교체한 친구지속 집단(different stable group)', 처음 에는 친구가 없었으나 5개월 이후에는 친구가 있으면 '친구형 성 집단(gain group)', 처음에는 친구가 있었으나 5개월 이후에 
Table 1

Profile of Friendship Patterns over Time 1 and Time 2

\begin{tabular}{ll}
\hline \multicolumn{1}{c}{ Friendship patterns } & \multicolumn{1}{c}{ Criteria of friendship stability and change } \\
\hline Same-stable friendships & Children maintained at least one mutual friend in Time 1 and Time 2 with the same peer \\
Different-stable friendships & Children had at least one mutual friend in Time 1 and 2 with different peers \\
Friendship gain & Children did not have any mutual friend in Time 1 but had at least one in Time 2 \\
Friendship loss & Children had at least one mutual friend in Time 1 but none in Time 2 \\
Chronically friendless & Children had no mutual friend in Time 1 and Time 2 \\
\hline
\end{tabular}

는 친구가 없으면 '친구상실 집단(loss group)', 처음에도 친구 가 없었고 5개월 이후에도 친구가 없으면 “친구형성 불가 집단 (chronically friendless group)'으로 분류하였다.

유아가 지명한 친구 중에서 상호 지명된 친구 쌍이 여러 명 인 경우는 동일한 친구지속 집단의 가능성을 먼저 고려하였 다. 따라서 해당 유아가 한명이라도 동일한 친구와 친구관계 가 유지되었으면 동일한 친구지속 집단으로 분류하였다.

\section{3. 연구 절차 및 분석}

본 연구에서는 유아가 친구를 지명하도록 하는 또래 지명 법을 잘 이해하는지의 여부와 소요시간을 알아보고자 유치원 2곳의 만 5세 유아 55명을 대상으로 예비 조사를 실시하였다. 발달이 느린 편이고 낯선 사람에 대한 경계가 심하다는 1 명의 유아를 제외하고는 대부분의 유아가 어려움 없이 친구를 지명 하였다.

본 조사는 서울, 인천, 경기도에 위치한 7 개의 유치원에서 18 개 학급을 임의 선정하고 만 5 세 반에 재원 중인 유아를 대 상으로 실시하였다. 교육기관의 환경적 특성은 통제하기 위하 여 유치원에 재원하고 있는 유아만을 대상으로 하였고, 유치 원에서 한 학급의 인원은 20 명 이상 30 명 이내의 학급으로 제 한하였다.

1차 조사는 2013년 7월 중순에 547명을 대상으로 자료를 수집하였다. 2차 조사는 2013년 12월 중순에 실시하였으며 1 차 조사 후 교사의 전근으로 연구에 참여하지 못하게 된 30명, 이사 등의 이유로 유치원을 퇴소한 14 명과 장기 결석으로 친 구 관계 조사를 실시하지 못하게 된 유아 2명을 제외한 501명 을 대상으로 실시하였다.

본 연구에서 수집된 자료는 SPSS 20.0 (IBM Co., Armonk, $\mathrm{NY}$ ) 프로그램을 사용하여 남아와 여아에 대해 각각 친구관계 수의 평균, 표준편차, 빈도와 백분율을 산출하였다. 친구관계 안정성 및 변화유형의 빈도와 백분율을 산출하였고 성에 따라 친구관계 안정성에 차이가 있는지 살펴보기 위하여 $\chi^{2}$ 검증
을 실시하였다.

\section{연구결과}

1. 남아와 여아의 친구 수

본 연구에서는 유아에게 친한 친구를 3 명씩 지명하게 하였는 데, 유아가 친구라고 지명한 유아의 수는 Table 2 와 같다. 친구 수를 살펴보면, 남아는 1차 시기에 친구가 없는 비율이 $33.1 \%$ 로 가장 많았고, 여아는 1 명의 친구가 있는 비율이 $35.9 \%$ 로 가 장 많았다. 2 차 시기에, 남아는 친구가 1 명인 경우가 $31.4 \%$ 로 가장 많았고, 여아는 1 명 친구가 있는 비율과 2 명 친구가 있는 비율이 $32.1 \%$ 로 동일하게 많았다.

학기 중간쯤인 7월의 1 차 조사에서는 유아가 평균 1.2 명(남 1.2 , 여 1.2 )을 친구라고 지명하였고, 5 개월 후인 12 월의 2 차 조 사에서는 평균 1.4 명(남 1.4 , 여 1.5)을 친구로 지명하였다. 즉 학기가 진행 되면서 친구가 있는 유아의 수는 증가하고 친구 가 없는 유아는 줄었으며, 한 명의 유아가 형성하고 있는 친구 수가 약간 증가하는 경향이 있었다.

성에 따른 친구 수의 차이를 $\chi^{2}$ 검증한 결과, Time $1\left(\chi^{2}=\right.$ $5.72, \mathrm{~ns})$ 과 Time $2\left(\chi^{2}=4.15, \mathrm{~ns}\right)$ 시기 모두 성차는 통계적으로 유의하지 않았다. 이는 Time 1 과 Time 2 시기 모두 남아와 여 아가 형성하는 친구 수에 차이가 없음을 의미하였다.

\section{2. 친구관계 변화 유형별 친구 수}

본 연구에서는 친구관계의 변화유형 별로 친구의 수에 차이가 있는지 살펴보고자 상호 지명한 친구의 수를 분석하였다. 친 구관계의 변화 유형에 따른 친구 수의 분포와 평균 및 표준편 차는 Table 3에 제시하였다.

먼저 동일한 친구지속 집단은 1,2 차 시기 모두 2 명과 친 
구관계를 형성한 경우가 각각 $40.2 \%, 39.7 \%$ 로 가장 많았고, 그 다음으로 1 차 시기에는 1 명과 친구관계를 형성한 경우가 $32.0 \%, 2$ 차 시기에는 3 명과 친구관계를 형성한 경우가 $33.3 \%$ 로 많았다. 교체한 친구지속 집단, 친구형성 집단과 친구상실 집단은 1 명과 친구관계를 형성한 경우가 가장 많았다.

동일한 친구지속 집단은 1 차와 2 차에 평균 $2.0,2.1$ 명의 친 구가 있었고, 교체한 친구지속 집단은 평균 1.4 명의 친구를 사
귀었다. 친구형성 집단은 2 차 시기에 평균 1.5 명의 친구, 친구 상실 집단은 1 차 시기에 평균 1.4 명의 친구를 사귀었다.

\section{3. 친구관계의 변화 유형}

본 연구에서는 유아가 친한 친구를 3 명 지명하고 5 개월 후 에 재지명 한 후 친구관계의 변화유형을 동일한 친구지속, 교

Table 2

The Number and Means of Friends in Time 1 and Time 2 by Sex

$(N=501)$

\begin{tabular}{|c|c|c|c|c|}
\hline \multirow[b]{2}{*}{ Time } & \multirow[b]{2}{*}{ No. of friends } & $\begin{array}{c}\text { Boys } \\
(n=239)\end{array}$ & $\begin{array}{c}\text { Girls } \\
(n=262)\end{array}$ & $\begin{array}{c}\text { Total } \\
(N=501)\end{array}$ \\
\hline & & $n(\%)$ & $n(\%)$ & $n(\%)$ \\
\hline \multicolumn{5}{|c|}{ Time 1} \\
\hline & One & $70 \quad(29.3)$ & $(35.9)$ & (32.7) \\
\hline & Two & $54 \quad(22.6)$ & $69 \quad(26.3)$ & $123 \quad$ (24.6) \\
\hline & Three & $36 \quad(15.1)$ & $(13.0)$ & (14.0) \\
\hline & No friends & $79 \quad(33.1)$ & $65 \quad(24.8)$ & $144 \quad(28.7)$ \\
\hline & $M(S D)$ & $1.2(1.0)$ & $1.2(1.0)$ & $1.2(1.0)$ \\
\hline \multicolumn{5}{|c|}{ Time 2} \\
\hline & One & $75 \quad(31.4)$ & $84 \quad(32.1)$ & (31.7) \\
\hline & Two & $66 \quad(27.6)$ & $(32.1)$ & (29.9) \\
\hline & Three & $37 \quad(15.5)$ & $46 \quad(17.6)$ & (16.6) \\
\hline & No friends & $61 \quad(25.5)$ & $48 \quad(18.3)$ & $109 \quad(21.8)$ \\
\hline & $M(S D)$ & $1.4 \quad(1.0)$ & $1.5(1.0)$ & $1.4 \quad(1.0)$ \\
\hline
\end{tabular}

Table 3

The Number and Means of Friends in Time 1 and Time 2 by Friendship Groups

$(N=501)$

\begin{tabular}{|c|c|c|c|c|c|c|c|c|c|c|}
\hline \multirow{2}{*}{$\begin{array}{l}\text { Time } \\
\text { Time } 1\end{array}$} & \multirow[b]{2}{*}{ No. of friends } & \multirow{2}{*}{\multicolumn{2}{|c|}{$\begin{array}{l}\text { Same-stable friendships } \\
\qquad(n=219)\end{array}$}} & \multirow{2}{*}{\multicolumn{2}{|c|}{$\begin{array}{l}\begin{array}{c}\text { Different- } \\
\text { stable friendships } \\
(n=90)\end{array} \\
n(\%)\end{array}$}} & \multirow{2}{*}{\multicolumn{2}{|c|}{$\begin{array}{c}\begin{array}{c}\text { Friendship } \\
\text { gain } \\
(n=85)\end{array} \\
n(\%)\end{array}$}} & \multirow{2}{*}{\multicolumn{2}{|c|}{$\begin{array}{c}\begin{array}{c}\text { Friendship } \\
\text { loss } \\
(n=49)\end{array} \\
n(\%)\end{array}$}} & \multirow{2}{*}{$\begin{array}{c}\begin{array}{c}\text { Chronically } \\
\text { friendless } \\
(n=58)\end{array} \\
n(\%)\end{array}$} \\
\hline & & & & & & & & & & \\
\hline & One & 70 & (32.0) & 63 & $(70.0)$ & & - & 32 & (65.3) & - \\
\hline & Two & 88 & $(40.2)$ & 21 & (23.3) & & - & 14 & (28.6) & - \\
\hline & Three & & $(27.9)$ & 6 & $(6.7)$ & & - & 3 & $(6.1)$ & - \\
\hline & $M(S D)$ & 2.0 & $(.8)$ & 1.4 & (.6) & & - & 1.4 & (.6) & - \\
\hline \multicolumn{11}{|l|}{ Time 2} \\
\hline & One & 59 & $(26.9)$ & 54 & $(60.0)$ & 48 & $(56.5)$ & & - & - \\
\hline & Two & 87 & $(39.7)$ & 32 & (35.6) & 31 & (36.5) & & - & - \\
\hline & Three & 73 & $(33.3)$ & 4 & $(4.4)$ & 6 & $(7.1)$ & & - & - \\
\hline & $M(S D)$ & 2.1 & $(.8)$ & 1.4 & (.6) & 1.5 & $(.7)$ & & - & - \\
\hline
\end{tabular}


Table 4

The Number of Children in Five Friendship Groups over Five Months

$(N=501)$

\begin{tabular}{|c|c|c|c|}
\hline & Boys & Girls & Total \\
\hline Groups & $n(\%)$ & $n(\%)$ & $n(\%)$ \\
\hline Same-stable friendships & $93 \quad(39.0)$ & $126(48.1)$ & $219 \quad(43.7)$ \\
\hline Different-stable friendships & $42 \quad(17.6)$ & $48 \quad(18.3)$ & $90 \quad(18.0)$ \\
\hline Friendship gain & $44 \quad(18.3)$ & $41 \quad(15.6)$ & $85 \quad(17.0)$ \\
\hline Friendship loss & $25 \quad(10.5)$ & $24 \quad(9.2)$ & $49 \quad(9.8)$ \\
\hline Chronically friendless & $35 \quad(14.6)$ & $(8.8)$ & $58 \quad(11.5)$ \\
\hline Total & $239(100)$ & $262(100)$ & $501(100)$ \\
\hline
\end{tabular}

Table 5

Sex Difference in Friendship Stability over Five Months

$(N=443)$

\begin{tabular}{|c|c|c|c|}
\hline & Boys & Girls & Total \\
\hline Groups & $n(\%)$ & $n(\%)$ & $n(\%)$ \\
\hline Friendship stability & $93 \quad(45.6)$ & $126(54.4)$ & $219(49.8)$ \\
\hline Friendship unstability & $111 \quad(54.4)$ & 113 (46.6) & $224 \quad(50.2)$ \\
\hline Total & $204(100)$ & $239(100)$ & $443(100)$ \\
\hline
\end{tabular}

체한 친구지속, 친구형성, 친구상실, 친구형성 불가 집단의 5 개 범주로 분류하였다(Proulx \& Poulin, 2013; Wojslawowicz Bowker et al., 2006). 5개월에 걸친 유아의 친구 관계를 살펴 보면 Table 4에 제시한 바와 같이 5개월 후에도 동일한 유아 와 친구관계를 지속하고 있는 동일한 친구지속 집단이 $43.7 \%$ 로 가장 많았다(남아 $39.0 \%$, 여아 $48.1 \%$ ). 그 다음으로 동일 한 친구는 아니지만 5 개월 후에도 친구가 있는 교체한 친구지 속 집단이 $18.0 \%$ 로 많았다(남아 $17.6 \%$, 여아 $18.3 \%$ ). 처음에 는 친구가 없었으나 5 개월 후에 친구가 있는 친구형성 집단이 $17.0 \%$ (남아 $18.3 \%$, 여아 $15.6 \%$ ), 처음에는 친구가 있었으나 5 개월 후에는 친구가 없는 친구상실 집단이 9.8\%(남아 $10.5 \%$, 여아 9.2\%), 처음에도 친구가 없었고 5개월 후에도 친구가 없 는 친구형성 불가 집단이 $11.5 \%$ (남아 $14.6 \%$, 여아 $8.8 \%$ )로 나 타났다. 동일한 친구지속 집단은 여아가 남아보다 상대적으로 많은 경향이 있었다. 친구형성 불가 집단은 남아가 여아보다 상대적으로 많은 경향이 있었다. 친구관계의 변화 유형에 대 한 5 개 집단의 $\chi^{2}$ 검증을 실시한 결과, 친구관계의 변화 유형 은 성에 따라 통계적으로 유의하지 않았다 $\left(\chi^{2}=6.87, n s\right)$.

\section{4. 친구관계의 안정성에 대한 성차}

5 개월 동안 친구 관계에서 안정성을 보인 유아와 불안정한 친
구 관계를 보인 유아의 수가 성에 따라 차이가 있는지를 살펴 보았다. 이를 위해 1 명 이상의 동일한 친구와 5 개월 동안 친구 관계를 유지한 동일한 친구지속 집단은 친구관계의 안정성 집 단으로, 친구관계에서 유대감의 변화를 보인 교체한 친구 지속 집단, 친구형성 집단, 친구상실 집단은 불안정한 집단으로 구 분하여 $\chi^{2}$ 검증을 실시하고 그 결과를 Table 5 에 제시하였다.

남아와 여아는 친구관계 안정성 집단 대 불안정한 집단의 성차가 통계적으로 유의하지 않았다 $\left(\chi^{2}=2.65, n s\right)$. 이는 남아 와 여아가 단기 종단적으로 친구관계가 유지되거나 변화하는 데 유의한 차이를 나타내지 않는 경향이 있음을 의미하였다.

\section{논의 및 결론}

본 연구는 만 5세 유아를 대상으로 5개월 동안 친구관계의 안 정성 및 변화유형이 어떠한지 살펴보고 친구관계 안정성은 성 에 따른 차이가 있는지 알아보고자 하였다. 유아가 또래 지명 법을 통해 친한 친구를 지명하고 5개월이 지나서 반복 측정하 여 친구가 있는지 유무와 동일한 유아가 친구인지를 기준으 로 친구관계의 변화 유형을 5 개로 분류한 결과, 동일한 유아 와 친구관계를 지속하고 있는 동일한 친구지속 집단의 비율이 $43.7 \%$ 로 가장 많았다. 두 번째로는 동일한 친구는 아니지만 5 
개월 후에도 친구가 계속 있는 교체한 친구지속 집단이 $18.0 \%$ 였다. 친구가 없었다가 5 개월 후에 친구가 형성된 친구형성 집 단은 $17.0 \%$, 친구가 없었는데 5 개월 후에도 계속 없는 친구형 성 불가 집단은 $11.5 \%$, 친구가 있었으나 5 개월 후에는 친구를 잃게 되는 친구상실 집단은 $9.8 \%$ 로 가장 적었다.

본 연구 결과는 Proulx와 Poulin (2013)이 2,353명의 캐나다 유아를 대상으로 친구관계의 변화유형을 살펴본 연구에서, 동 일한 친구지속 집단이 $39.9 \%$, 교체한 친구지속 집단이 $20.1 \%$, 친구형성 집단이 $15.4 \%$, 친구상실 집단이 $12.6 \%$, 친구형성 불 가 집단이 $11.0 \%$ 로 나타난 결과와 유사하였다. 3 세부터 친구 관계가 유아의 삶에서 중요해지고 이사 등의 이유로 또래집단 내에 있는 유아가 다른 곳으로 떠나지 않는다면 다수의 유아 가 친구관계를 형성하고 유지할 수 있다고 주장하는 선행 연 구의 결과와 맥을 같이 한다고 볼 수 있다(Gershman \& Hayes, 1983; Howes, 1988, 1990).

초등학교 3, 4학년을 대상으로 캐나다와 태국의 친구관계 안정성을 비교한 Benjamin, Schneider, Greenman과 Hum (2001) 의 연구 그리고 캐나다와 이탈리아를 비교한 Schneider, Fonzi, Tani와 Tomade (1997)의 연구들은 친구관계 안정성에 국가 간 차이가 나타나지 않았다. 국가마다 문화적 차이가 나타나고 이로 인해 어머니와 교사가 지향하는 대인관계 기술과 가치관 에 차이가 있음에도 불구하고 같은 연령 내에서 친구관계를 형성하고 유지하는 비율은 문화적 차이를 넘어서는 보편적인 발달 과정일 수 있음을 시사하는 것이었다.

유아가 친구를 사귀는 것은 공동 주의, 인과적 관계의 이해, 모방, 언어, 정서조절과 같은 많은 기술을 필요로 하는 도전적 인 일이다(Hay, Payne, \& Chadwick, 2004). 그럼에도 불구하고 본 연구에서 나타난 바와 같이 $88.5 \%$ 에 달하는 대부분의 유아 는 5 개월 동안 한 명 이상과 친구관계를 형성하였고, $43.7 \%$ 의 유아는 동일한 친구와 관계를 유지할 수 있었다. 이는 유아기 의 친구관계가 도전적인 일이면서도 보편적인 사회화 과정이 라는 것을 나타내 주고, 유아기 후반에는 친구와 상호관계를 갖고 친구관계를 유지하기도 하는 발달적 특성을 나타내는 것 이었다.

또한 유아의 $18 \%$ 는 5 개월 동안 친구가 바뀌었고, $17 \%$ 는 친구가 없다가 있게 되었고 $9.8 \%$ 는 친구가 있었는데 없어지 게 되었다. 이처럼 유아는 동일한 친구와 친구관계를 유지하 기도 하지만 친한 친구를 바꾸거나 새롭게 친구를 사귀거나 반대로 친구를 잃기도 한다. 이러한 결과는 단기적으로 유아 의 친구관계가 변화할 수 있음을 보여주어 유아기 친구관계의 특성을 반영하였다고 볼 수 있다.
유아의 친구관계는 새로 발견된 관심사나 어떤 옷, 공유 활동 또는 놀이 양식의 변화에 따라 친구가 결정될 수 있다 (Kostelnik et al., 2009). 즉, 자신이 좋아하는 것, 공유 활동, 놀 이 양식이 변함에 따라 친구관계도 바뀔 수도 있음을 유추할 수 있다. 그러나 본 연구에서는 놀이 맥락의 변화 때문에 친구 관계가 변화했는지 또는 어떤 요인에 의해서 친구가 생겼거나 바뀌었는지 등은 파악할 수 없었으므로 추후 연구에서 친구관 계의 변화가 어떤 요인에 의해 영향을 받는지 파악해볼 필요 가 있다.

본 연구 결과에 의하면, 적지 않은 수인 $11.5 \%$ 의 유아가 5 개 월 동안 계속 친구가 없었다. 선행연구에서 보면, 친구가 없는 유아는 한 명 이상의 친구가 있는 유아에 비해 공격성, 위축, 수줍음이 높고, 친사회성이 낮았으며(Proulx \& Poulin, 2013) 사회적 기술이 낮았다(Engle, McElwain, \& Lasky, 2011; Vaughn et al., 2000). 이들은 또래와 놀이를 시작하고 긍정적인 놀이 상호작용을 유지하는 데에도 어려움이 있었다(Newcomb \& Bagwell, 1995). 친구가 없는 유아는 또래의 놀이에 참여하려고 하지 않고 쳐다보고 있거나 언어적 표현을 적게 하는 경향이 있었다(Roopnarine \& Field, 1984). 본 연구는 같은 학급에서 한 학기를 지낸 유아들에게 7월과 학년 말인 12월에 친구관계를 조사하였다. 거의 일 년에 가까운 시간을 같은 또래들과 함께 놀이하고 일상생활을 공유했음에도 불구하고 계속 친구가 없 는 유아는 또래관계 형성에 어려움이 있다고 간주할 수 있다.

본 연구에서는 심리적 적응 문제를 살펴보지 않아서 친구가 없는 유아가 실제로 문제가 있는지는 파악할 수 없지만 친구 가 없었던 유아는 계속 친구가 없을 가능성이 높았고(Howes \& Phillipsen, 1992; Ladd \& Troop-Gordon, 2003; Quinn \& Hennessy, 2010) 유아기 또래관계에 문제가 있음은 심리적 적응 문제의 원인이자 결과일 수 있음을 보고한 연구들이 있다(Bukowski, Buhrmester, \& Underwood, 2011; Hay et al., 2004). 그러므로 추 후 연구에서는 이들의 심리 사회적 적응, 개인적인 특성이나 대인관계적인 특성을 파악하여 중재의 필요성을 확인함으로 써 연속적인 또래관계 문제를 예방 할 필요가 있을 것이다.

친구가 있었으나 5개월 후에는 친구가 없는 친구상실 집 단 유아도 주목해볼 필요가 있다. 선행연구에서는 이들이 친 구형성 불가 집단과 유사한 특성을 보이는 것으로 나타났다 (Wojslawowicz Bowker et al., 2006), 이들은 점차 사회적 유능감 이 낮아지거나 수줍음이 증가하고 또래 수용도가 줄어드는 결 과를 보이며 전반적인 또래관계와 사회적 적응에 어려움이 있 었다(Howes, 1988; Proulx \& Poulin, 2013). 따라서 추후 연구에 서는 이들을 추적 조사하여 사회적 적응이 어떻게 변화하는지 
를 살펴볼 필요가 있다.

5 개월의 기간 동안 친구관계를 형성하는데 있어서, 동일한 친구와 친구관계를 계속 유지하며 친구관계의 안정성을 보이 는 유아와 친구관계의 유대감에 변화를 보이며 친구관계의 불 안정성을 보였던 유아들이 성에 따라 차이가 있는지를 살펴 보았다. 친구관계를 유지하고 변화를 보이는데 있어서는 성 차를 보이지 않았다. 이는 단기 종단적으로 친구관계의 안정 성에 성차가 없었다고 보고한 선행연구와 일치하는 결과였고 (Cairns et al., 1995; Proulx \& Poulin, 2013), 성차가 보고된 선행 연구와는 상이한 결과였다(Howes \& Philipsen, 1992; Schneider et al., 1997). 이는 남아와 여아가 친구관계를 형성하고 유지해 나가는 데 있어서 다른 발달 과정을 경험하기 보다는 유사한 발달 과정을 경험할 수 있음을 시사하는 결과라고 할 수 있다.

친구관계의 안정성에서 성차가 있다고 보고한 대부분의 선 행연구는 학령기 아동을 대상으로 한 연구였다(Benenson \& Christakos, 2003; Rose \& Rudolph, 2006). 연구자들은 여아가 남아보다 부정적인 정서를 더 민감하게 받아들이고 대인관계 적인 스트레스에 민감하므로 여아가 남아에 비해 친구를 쉽게 바꾸고 관계를 오래 유지하지 못한다고 해석하였다(Benenson \& Christakos, 2003; Rose \& Rudolph, 2006). 친구관계의 질적 인 측면을 살펴본 연구에서도 유아와 학령기 아동은 차이가 있었다. 학령기 아동을 대상으로 한 Parker와 Asher (1993)의 연 구에서는 여아가 남아에 비해 친구 간의 도움과 안내, 인정, 돌 봄, 개인적 친밀감이 더 높았다. 그러나 유아를 대상으로 한 Ladd 등(1996)의 연구에서는 남아와 여아의 친구관계의 질은 차이가 없었다.

이상에서 본 연구 결과와 선행연구를 종합해보면, 유아는 아직 대인관계적 스트레스와 친구 간 갈등에서의 정서적 반응 성 그리고 친구관계의 질에서 성차를 보이지 않기 때문에 친 구관계 안정성에도 성차를 보이지 않을 수 있음을 유추할 수 있다. 그러나 본 연구에서는 유아가 친구관계에서 갈등이 발 생했을 때 정서적 반응성이나 친구관계의 질에 성차가 있는지 를 살펴보지 않았으므로, 추후 연구에서는 이를 확인해볼 필 요가 있다.

지금까지 살펴본 바에 기초하여 본 연구 결과가 가지는 시 사점과 의의를 요약해보면 다음과 같다. 첫째, 본 연구 결과에 의하면, 유아의 $88.5 \%$ 는 5 개월 동안 한 명 이상 친구관계를 형 성하였고, 유아의 $43.7 \%$ 는 5 개월 동안 동일한 친구와 친구관 계를 유지하였다. 유아가 친한 친구관계를 형성하고 일정 기 간 동안 그 관계를 유지할 수 있는가에 대해서는 연구자들의 의견이 일치하지 않았다. 유아의 친구관계가 일시적인 순간의
놀이 상대에 불과하다고 설명하는가 하면(Selman, 1980), 몇 몇 연구자들은 유아의 친구관계도 지속적이며 인정과 돌봄의 특성을 보일 수 있다고 주장하였다(Ladd et al., 1996; Sebanc, 2003). 본 연구는 유아의 친구관계가 어느 정도 유지되거나 변 화하는지를 단기 종단적으로 검증해 봄으로써 유아들의 친구 관계 안정성에 대한 발달적 특성을 경험적으로 분석하였다는 데 의의가 있다.

둘째, 이제까지 국내에서 유아의 친구관계의 안정성과 변 화 유형을 조사한 연구는 거의 전무하였다. 본 연구는 우리나 라 유아들을 대상으로 친구관계의 안정성과 변화 유형을 살펴 봄으로써 국외 연구 결과와 비교해볼 수 있는 준거 자료를 제 공해 주었고, 이를 통해 친구관계의 안정성에 있어 발달적 보 편성이 있음을 시사해 주었다는데 의의가 있다.

셋째, 본 연구에서는 유아와의 개별적인 면접을 통해 친구 관계를 확인했으므로 유아가 어떻게 친구와 상호작용하고 놀 이하는지는 평가하지 않았다. 추후 연구에서는 친구 쌍에서 유아의 상호작용 행동을 관찰해서 유아가 친구와 어떤 상호작 용을 하는지 그리고 상호작용 행동이 친구관계를 유지하거나 변화하는데 어떻게 영향을 미치는지 살펴보아야 할 것이다. 결론적으로 만 5 세 유아는 5 개월 동안 친한 친구와 관계를 유 지하기도 하고 변화하기도 한다. 여아와 남아가 5 개월 동안 한 명 이상의 친구관계를 형성하거나 친구관계를 유지하거나 변 화하는 데는 성차를 보이지 않았다.

\section{Notes}

This article is a part of the first author's doctoral dissertation submitted in 2015, and was presented as a poster at the 2015 Annual Spring Conference of the Korean Association of Child Studies.

\section{Conflict of Interest}

No potential conflict of interest relevant to this article was reported.

\section{References}

Benenson, J. F., \& Christakos, A. (2003). The greater fragility of females' versus males' closest same-sex friendships. Child 
Development, 74, 1123-1129.

Benjamin, W. J., Schneider, B. H., Greenman, P. S., \& Hum, M. (2001). Conflict and childhood friendship in Taiwan and Canada. Canadian Journal of Behavioral Science, 33(3), 203-211.

Berndt, T. J., Hawkins, J. A., \& Hoyle, S. G. (1986). Changes in friendship during a school year: Effects on children's and adolescents' impressions of friendship and sharing with friends. Child Development, 57(5), 1284-1297.

Bukowski, W. M., Buhrmester, D., \& Underwood, M. K. (2011). Peer relations as a developmental context. In M. K. Underwood, \& L. H. Rosen (Eds.), Social development: Relationships in infancy, childhood, and adolescence (pp. 153179). New York, NY: Guilford Press.

Bukowski, W. M., \& Newcomb, A. F. (1984). Stability and determinants of sociometric status and friendship choice: A longitudinal perspective. Developmental Psychology, 20(5), 941-952.

Bukowski, W. M., \& Newcomb, A. F., \& Hoza, B. (1987). Friendship conceptions among early adolescents: A longitudinal study of stability and change. Journal of Early Adolescence, 7, 143-152.

Cairns, R. B., Leung, M. C., Buchanan, L., \& Cairns, B. D. (1995). Friendships and social networks in childhood and adolescence: Fluidity, reliability, and interrelations. Child Development, 66(5), 1330-1345.

Cillessen, A. H. N. (2009). Sociometric methods. In K. H. Rubin, W. M. Bukowski, \& B. Laursen (Eds.), Handbook of peer interactions, relationships, and groups (pp. 82-99). New York, NY: The Guilford Press.

Engle, J. M., McElwain, N. L., \& Lasky, N. (2011). Presence and quality of kindergarten children's friendships: Concurrent and longitudinal associations with child adjustment in the early school years. Infant and Child Development, 20(4), 365-386.

Erwin, P. (1993). Friendship and peer relations in children. Chichester, UK: Wiley \& Sons.

Fabes, R. A., Hanish, L. D., \& Martin, C. L. (2003). Children at play: The role of peers in understanding the effects of child care. Child Development, 74(4), 1039-1043.

Furman, W. (1996). The measurement of friendship perceptions: Conceptual and methodological issues. In W. M. Bukowski, A. F .Newcobm, W. W. Hartup (Eds.), The company they keep: Friendship in childhood and adolescence (pp. 41-65). New York, NY: Cambridge University Press.

Gershman, E. S., \& Hayes, D. S. (1983). Differential stability of reciprocal friendships and unilateral relationships among preschool children. Merrill-Palmer Quarterly, 29(2), 168177.

Gifford-Smith, M. E., \& Brownell, C. A. (2003). Childhood peer relationships: Social acceptance, friendships and peer networks. Journal of School Psychology, 41(4), 235-284.

Gottman, J. M. (1983). How children become friends. Monograhps of the Society for Research in Child Development. 48(3), 1-83.

Hay, D. F., Payne, A., \& Chadwick, A. (2004). Peer relations in childhood. Journal of Child Psychology and Psychiatry, 45(1), 84-108.

Howes, C. (1988). Peer interaction of young children. Monographs of the Society for Research in Child Development, 53(1), 1-92.

Howes, C. (2009). Friendship in early childhood. In K. H. Rubin, W. M. Bukowski, \& B. Laursen (Eds.), Handbook of peer interactions, relationships, and groups (pp. 180-194). New York, NY: The Guilford Press.

Howes, C., \& Phillipsen, L. (1992). Gender and friendship: Relationships with peer groups of young children. Social Development, 1(3), 230-242.

Kostelnik, M. J., Whiren, A. P., Soderman, A. K., \& Gregory, K. M. (2009). Guiding children's social development and learning (K. J. Park, S, Y, Kim, Y. H. Kwon, \& J. H. Kim Trans.). Paju, Korea: Gyomoon publishers. (Original work published 2008)

Ladd, G. W., \& Burgess, K. B. (1999). Charting the relationship trajectories of aggressive, withdrawn, and aggressive/ withdrawn children during early grade school. Child Development, 70(4), 910-929.

Ladd, G. W., Kochenderfer, B. J., \& Coleman, C. C. (1996). Friendship quality as a predictor of young children's early school adjustment. Child Development, 67(3), 1103-1118.

Ladd, G. W., \& Troop-Gordon, W. (2003). The role of chronic peer difficulties in the development of children's psychological adjustment problems. Child Development, 74(5), 1344-1367.

Lindsey, E. W. (2002). Preschool children's friendships and peer acceptance: Links to social competence. Child Study Journal, 32(3), 145-155.

Martin, C. L., \& Fabes, R. A. (2001). The stability and consequences of young children's same-sex peer interactions. Developmental Psychology, 37(3), 431-446.

Mendelson, M. J., Aboud, F. E., \& Lanthier, R. P. (1994). Personality predictors of friendship and popularity in kindergarten. Journal of Applied Developmental Psychology, 15(3), 413-435.

Newcomb, A. F., \& Bagwell, C. L. (1995). Children's friendship relations: A meta-analytic review. Psychological Bulletin, 117, 306-347.

Parker, J. G., \& Asher, S. R. (1993). Friendship and friendship quality in middle childhood: Links with peer group acceptance and feelings of loneliness and social dissatisfaction. Developmental Psychology, 29(4), 611-621.

Poulin, F., \& Chan, A. (2010). Friendship stability and change in 
childhood and adolescence. Developmental Review, 30(3), 257-272.

Proulx, M., \& Poulin, F. (2013). Stability and change in kindergarteners' Friendships: Exmination of links with social functioning. Social Development, 22(1), 111-125.

Quinn, M., \& Hennessy, E. (2010). Peer relationships across the preschool to school transition. Early Education and Development, 21(6), 825-842.

Roopnarine, J. L., \& Field, T. M. (1984). Play interactions of friends and acquaintances in nursey school. In T. Field, J. Roopnarine, \& M. Segal (Eds.), Friendships in normal and handicapped children (pp. 89-98). Norwood, NJ: Ablex.

Rose-Krasnor, L., \& Denham, S. (2009). Social-emotional competence in early childhood. In K. H. Rubin, W. M. Bukowski, \& B. Laursen (Eds.), Handbook of peer interactions, relationships, and groups (pp. 162-192). New York, NY: The Guilford Press.

Rose, A. J., \& Rudolph, K. D. (2006). A review of sex differences in peer relationships processes: Potential trade-offs for the emotional and behavioral development of girls and boys. Psychological Bulletin, 132, 98-131.

Rubin, K. H., Bukowski, W., \& Parker, J. G. (2006). Peer interactions relationships, and groups. In N. Eisenber, W. Damon, \& R. M. Lerner (Eds.), Handbook of child psychology: Social, emotional, and personality development (6th ed., Vol 3, pp. 571-645). Hoboken, NJ: John Wiley \& Sons Inc.

Rubin, K. H., Coplan, R. J., Chen, X., Buskirk, A. A., \& Wojslawowicz, J. C. (2005). Peer relationships in childhood. In M. H. Bornstein \& M. E. Lamb (Eds.), Developmental science: An advanced textbook (5th ed., pp. 469-512). Hillsdale, NJ: Lawrence Erlbauum Associates.

Schneider, B. H., Fonzi, A. F., Tani, F., \& Tomade, G. (1997). A cross-cultural exploration of the stability of children's friendships and the predictors of their continuation, Social Development, 6(3), 322-339.

Sebanc, A. M. (2003). The friendship features of preschool children:
Links with prosocial behavior and aggression. Social Development, 12(2), 249-268.

Sebanc, A. M., Kearns, K. T., Hernandez, M. D., \& Galvin, K. B. (2007). Predicting having a best friend in young children: Individual characteristics and friendship features. The Journal of Genetic Psychology, 168(1), 81-95.

Selman, R. L. (1980). The growth of interpersonal understanding: Developmental and clinical analysis. New York, NY: Academic Press.

Shin, N., Kim, M., Goetz, S., \& Vaughn, B. E. (2014). Dyadic analyses of preschool-aged children's friendships: Convergence and differences between friendship classifications from peer sociometric data and teacher's reports. Social Development, 23(1), 178-195.

Vaughn, B. E., Azria, M. R., Krzysik, L., Caya, L. R., Bost, K. K., Newell, W., \& Kazura, K. L. (2000). Friendship and social competence in a sample of preschool children attending head start. Developmental Psychology, 36(3), 326-338.

Wojslawowicz Bowker, J. C., Rubin, K. H., Burgess, K. B., BoothLaForce, C., \& Rose-Krasnor, L. (2006). Behavioral characteristics associated with stable and fluid best friendship patterns in middle childhood. Merrill-Palmer Quarterly, 52(4), 671-693.

\section{ORCID}

Mi Hyun Park http://orcid.org/0000-0002-8703-0186

Kyung Ja Park http://orcid.org/0000-0003-2865-0788

Received November 30, 2015

Revision received February 16, 2016

Accepted February 16, 2016 